\title{
Unusual case of diabetic ketoacidosis
}

\author{
J ohad F. Khoury¹, Daniel A. King ${ }^{2}$, Eyal Braun ${ }^{3}$, Mohammad E. Naffaa ${ }^{4}$ \\ 1. Department of Internal Medicine B, Rambam Health Care Campus, Haifa, Israel. 2. Intensive Care Unit, Medical \\ Division, Rambam Health Care Campus, Haifa, Israel. 3. Department of Internal Medicine H and the Infectious Diseases \\ Unit, Rambam Health Care Campus and the Rappaport's Faculty of Medicine, the Technion, Haifa, Israel. 4. Department of \\ Internal Medicine $\mathrm{H}$ and the B. Shine Rheumatology Unit, Rambam Health Care Campus and the Rappaport's Faculty of \\ Medicine, the Technion, Haifa, Israel.
}

Correspondence: Mohammad E. Naffaa. Address: Haa'leya Hashneya 8, Bat-Galim, 31096, Haifa, Israel.

Email: m_naffaa@rambam.health.gov.il

Received: December 10, 2014

Accepted: December 21, 2014 Online Published: December 29, 2014

DOI : $10.5430 /$ crim.v2n1p96

URL: http://dx.doi.org/10.5430/crim.v2n1p96

\section{Abstract}

Type-2 Diabetes mellitus may present in several ways, one of which, is Diabetic Ketoacidosis. Diabetes itself may be caused by acute pancreatitis. We discuss a case of 46 years old male, with no history of diabetes mellitus, who was admitted for abdominal pain and vomiting, and finally diagnosed with diabetic ketoacidosis. Serum amylase and lipase could not be measured at admission owing to the heavily lipemic serum. Subsequent measures demonstrated very high levels of lipase. Serum triglycerides were significantly elevated; $3200 \mathrm{mg} / \mathrm{dl}$. Initial computed tomography scan of the abdomen did not reveal findings typical for acute pancreatitis.

Hypertriglyceridemia-induced pancreatitis leading to overt diabetic ketoacidosis in a previously non-diabetic patient was our leading diagnosis. Lipo-pharesis was instituted shortly after the initiation of intra-venous insulin and fluid resuscitation. Subcutaneous heparin and fibrates were added later on, leading to clinical improvement, and reduction in serum triglycerides and pancreatic enzymes.

\section{Keywords}

Diabetic ketoacidosis, Pancreatitis, Lipo-pharesis, Hypertriglyceridemia, Lipase

\section{I ntroduction}

The natural history of type 2 diabetes mellitus (DM-2) usually includes a symptomatic period of polyuria, polydepsia, and weight loss and the diagnosis can be delayed years after the onset of the initial symptoms. The diagnostic criteria include a single test of hemoglobin A1C $>6.5 \%$, or one of the following tests in two separate measurements: fasting plasma glucose $>126 \mathrm{mg} / \mathrm{dl}$, plasma glucose $>200 \mathrm{mg} / \mathrm{dl} 2$ hours after 75 gr glucose load, or plasma glucose $>200 \mathrm{mg} / \mathrm{dl}$ in a random measurement in a patient with classic symptoms of hyperglycemia ${ }^{[1]}$.

DM-2 may be caused or worsened by acute pancreatitis, with hypertriglyceridemia being the third most common cause of pancreatitis, preceded only by gallstone and alcohol ${ }^{[2]}$. 
We report a case of diabetic ketoacidosis developing in a non-diabetic patient, complicating hypertriglyceridemiainduced acute pancreatitis.

\section{Case presentation}

A 46 years old male was admitted to the emergency room because of generalized abdominal pain and vomiting in the preceding three days. His medical history included morbid obesity, active schizophrenia and active heavy smoking. Permanent medications included Simvastatin, Biperiden and Carbamazepine. One year before his current admission, he was admitted to hospital with perforated appendicitis, due to which he was operated and had a complicated hospitalization with prolonged mechanical ventilation.

Physical examination was notable for pale wet skin, normal blood pressure 135/83 mmHg, tachycardia with 117 beats per minute, body temperature was 37.3 Celsius degrees, tachypnea consistent with Kussmaul respiration with 40 breaths per minute. Blood oxygen saturation was $98 \%$ on nasal canula. Abdomen was soft, with a non-incarcerated postoperative ventral hernia at the surgical scar site, with no tenderness, rebound or guarding. The rest of the physical examination was unrevealing. Relevant laboratory parameters are shown in Table 1.

Table 1. Relevant laboratory parameters

\begin{tabular}{lll}
\hline Parameter & Value & Normal ranges and Units \\
\hline White blood count & 13.6 & $4-10.8103 / \mu \mathrm{l}$ \\
$\mathrm{pH}$ & 7.07 & $7.35-7.45$ \\
$\mathrm{PCO}_{2}$ & 14.7 & $35-45 \mathrm{mmHg}$ \\
Bicarbonate & 4.3 & $22-26 \mathrm{mmol} / \mathrm{l}$ \\
Lactate & 1.6 & $0-1.3 \mathrm{mmol} / \mathrm{l}$ \\
Glucose & 618 & $70-99 \mathrm{mg} / \mathrm{dl}$ \\
Creatinine & 2.1 & $0.4-1.3 \mathrm{mg} / \mathrm{dl}$ \\
Blood urea nitrogen & 26 & $5-20 \mathrm{mg} / \mathrm{dl}$ \\
Urine ketones & Positive & \\
\hline
\end{tabular}

Serum amylase and lipase could not be measured due to the extremely lipemic serum. Initial abdominal computed tomography scan demonstrated a non-incarcerated hernia at the surgical site, with no evidence of acute pancreatitis. The day after, serum amylase, lipase, triglycerides, and C-reactive protein were measured and were as follows: 65 U/L, 2932 U/L, $3191 \mathrm{mg} / \mathrm{dl}$ and $476 \mathrm{mg} / \mathrm{L}$, respectively. Five days later the hemoglobin A1C was 14.6\%. Intravenous fluids and insulin were instituted. Serum glucose and electrolytes were closely monitored, while the patient was kept on Nothing Per Os. Because of agitation and impending respiratory failure, the patient was intubated and transferred to the intensive care unit for further work-up and treatment. Later on, subcutaneous heparin, lipopharesis and fibrates were initiated, with resultant improvement.

The patient's metabolic state was controlled within three days. Blood glucose was lowered, bicarbonate increased, $\mathrm{pH}$ normalized and the triglycerides level decreased sharply and steadily.

Interestingly, the patient was tapered-off gradually from insulin or any other hypoglycemic or anti-hyperglycemic medications, maintaining normal fasting glucose levels. In a follow-up visit the patient was feeling well with no evidence of diabetes. 


\section{Discussion}

We presented an unusual case of diabetic ketoacidosis in a non-diabetic patient, complicating the clinical course of hypertriglyceridemia-induced pancreatitis.

The typical presentations of DM-2 usually include the subacute or chronic constellation of the following symptoms: polydipsia, polyuria and weight loss ${ }^{[1]}$. In rare cases of DM-2, a fundamental event causes acute pancreatic failure leading to acute presentation of diabetes. Such major events may include pancreatic surgery (e.g. post trauma, Whipple procedure), or pancreatitis ${ }^{[3]}$.

Our patient presented with DKA as the presenting manifestation of acute pancreatitis and subsequently diabetes, while repeated glucose measurements during the prior months before admission were totally normal, supporting the diagnosis of new-onset diabetes. Kabadi, in 1995, described three patients who manifested with ketoacidosis at the time of presentation of acute pancreatitis. In none of these patients could the ketoacidosis be attributed to any of the well-known pathogenetic factors such as ethanol, diabetes mellitus or prolonged starvation but rather to acute pancreatitis ${ }^{[4]}$.

Regarding our patient, we suggest the following sequence of events:

Severe hypertriglyceridemia caused acute pancreatitis leading to acute pancreatic failure and consequently the development of overt DM and DKA; interestingly, when the patient recovered from pancreatic insufficiency, his blood glucose levels normalized even without anti hyperglycemic therapy. One might argue that normal glucose measurements prior to the current admission and the rapid onset of DM stand against DM-2. On the other hand, DM-1 is highly unlikely in 46 years old obese patient. It should be noted that the absence of tomographic evidence of pancreatitis does not rule out the diagnosis as it is known that the CT scan of the pancreas is normal in at least $20 \%-25 \%$ of patients with a clinical diagnosis of acute pancreatitis ${ }^{[5]}$. Whether a sharp elevation in serum glucose levels causes an immediate elevation of Hemoglobin A1C, is unclear.

Nair et al reported 100 cases of DKA showing that coexisting acute pancreatitis occurs in at least $10 \%-15 \%$ of cases, usually in severe episode of DKA with marked acidosis and hyperglycemia. They recommend that at least in DKA patients with abdominal pain, serum levels of amylase, lipase, and triglyceride should be measured and when one of these is markedly raised (> 3 times amylase and lipase or $>1000 \mathrm{mg} / \mathrm{dl}$ of triglyceride), a CT scan of the abdomen should be performed ${ }^{[6]}$. We strongly agree with the recommendation, especially in cases where the diagnosis of diabetes is not established.

The mechanism by which hypertriglyceridemia causes pancreatitis is based on the generation of free radical species through the hydrolysis of triglycerides by pancreatic lipase, and the release of free fatty acids that induce free radical damage. It is believed that triglycerides level higher than $1000 \mathrm{mg} / \mathrm{dl}$ can cause acute pancreatitis ${ }^{[7]}$. Serum amylase levels may be underestimated in hypertriglyceridemia, because of the triglycerides interference of the calorimetric reading. Serial dilutions of serum with saline solution allow correction to actual amylase in hyperlipemic serum ${ }^{[8]}$.

The primary goal in treating hypertriglyceridemia-induced pancreatitis is prevention. Pancreatitis can be prevented if triglycerides levels are lowered to normal or near normal levels. Fibrates may be used as the first agents to reduce triglycerides levels, but niacin and n-3 fatty acids may be used as well. We must emphasize the need of adequate control of glucose levels in diabetic patients and thyroid function in patients with hypothyroidism, as well as avoiding alcohol consumption, and the use of particular medications such as steroids, estrogen, hormonal replacement therapy, Olanzapine, Diprivan, and Thiazides. In cases where the use of a medication is necessary, such as anti HIV therapy or beta blockers, we must keep in mind the risk of secondary hypertriglyceridemia, especially in patients with high lipid levels, or with a lipoprotein abnormality type I or V, or in less common cases, type IV ${ }^{[9]}$. 
There are no definitive guidelines for treating this kind of pancreatitis, but insulin and heparin were used to decrease serum triglycerides by stimulating lipoprotein lipase activity, which degrades triglycerides into fatty acids and glycerol ${ }^{[10]}$. Small series has shown the benefit of intravenous insulin in triglyceride level reduction, but the optimal dose is unclear ${ }^{[11]}$. The benefit, dose or submission form of heparin is even more uncertain. The majority of cases describing the use of heparin were while using insulin as well. In some series the heparin was given intravenously while in others it was given subcutaneously. In one series low molecular weight heparin was used, while others used unfractionated heparin ${ }^{\text {[12] }}$.

Plasmapharesis is also used to remove triglycerides and chylomicrons from the serum, leading to reduction in plasma triglycerides which relieves the abdominal pain and improves the clinical state of the patient. In case series, plasmapharesis reduced triglycerides levels from above $5000 \mathrm{mg} / \mathrm{dl}$ to under 1000 after one session, while the minority of the patients needed two or three sessions ${ }^{[13]}$. Even though, the mortality reduction by using plasmapharesis in hypertrigylceridemic pancreatitis is still to be proved ${ }^{[14]}$.

In conclusion, diabetic ketoacidosis may be the presenting feature of acute pancreatitis in a non-diabetic patient, and in cases of diabetic ketoacidosis in the absence of diabetes, the diagnosis of acute pancreatitis and acute pancreatic failure should be sought. When treating patients with pancreatitis secondary to hypertriglyceridemia, the therapeutic regimen should include insulin, fibrates, heparin and plasmapharesis.

\section{References}

[1] American Diabetes Association. Diagnosis and classification of diabetes mellitus. Diabetes Care. 2014 Jan; 37 Suppl 1: S81-90. PMid:24357215 http://dx.doi.org/10.2337/dc14-S081

[2] Fortson MR, Freedman SN, Webster PD 3rd. Clinical assessment of hyperlipidemic pancreatitis. Am J Gastroenterol. 1995 Dec; 90(12): 2134-9. PMid:8540502

[3] Jalleh RP, Williamson RC. Pancreatic exocrine and endocrine function after operations for chronic pancreatitis. Ann Surg. 1992 Dec; 216(6): 656-62. PMid:1466619 http://dx.doi.org/10.1097/00000658-199212000-00007

[4] Kabadi UM. Pancreatic ketoacidosis: ketonemia associated with acute pancreatitis. Postgrad Med J. 1995 Jan; 71(831): 32-5. PMid:7708590 http://dx.doi.org/10.1136/pgmj.71.831.32

[5] Hill M, Barkin J, Isikoff M, et al. Acute pancreatitis clinical vs. CT findings. Am J Roentgenol. 1982; 139: 263-9. PMid:6979877 http://dx.doi.org/10.2214/ajr.139.2.263

[6] Nair S, Yadav D, Pitchumoni CS. Association of diabetic ketoacidosis and acute pancreatitis: observations in 100 consecutive episodes of DKA. Am J Gastroenterol. 2000 Oct; 95(10): 2795-800. PMid:11051350 http://dx.doi.org/10.1111/j.1572-0241.2000.03188.x

[7] Lindkvist B, Appelros S, Regnér S, et al. A prospective cohort study on risk of acute pancreatitis related to serum triglycerides, cholesterol and fasting glucose. Pancreatology. 2012 Jul-Aug; 12(4): 317-24. PMid:22898632 http://dx.doi.org/10.1016/j.pan.2012.05.002

[8] Brahm A, Hegele RA. Hypertriglyceridemia. Nutrients. 2013 Mar 22; 5(3): 981-1001. PMid:23525082 http://dx.doi.org/10.3390/nu5030981

[9] Fallat RW, Vester JW, Glueck CJ. Suppression of amylase activity by hypertriglyceridemia. JAMA. 1973 Sep 10; 225(11): 1331-4. PMid:4740657 http://dx.doi.org/10.1001/jama.1973.03220390031007

[10] Alagözlü H, Cindoruk M, Karakan T, et al. Heparin and insulin in the treatment of hypertriglyceridemia-induced severe acute pancreatitis. Dig Dis Sci. 2006 May; 51(5): 931-3. PMid:16670939 http://dx.doi.org/10.1007/s10620-005-9006-z

[11] Henderson SR, Maitland R, Mustafa OG, et al. Severe hypertriglyceridaemia in Type 2 diabetes mellitus: beneficial effect of continuous insulin infusion. QJM. 2013 Apr; 106(4): 355-9. PMid:23417910 http://dx.doi.org/10.1093/qjmed/hcs238

[12] Cole RP. Heparin treatment for severe hypertriglyceridemia in diabetic ketoacidosis. Arch Intern Med. 2009 Aug 10; 169(15): 1439-41. PMid:19667310 http://dx.doi.org/10.1001/archinternmed.2009.221 
[13] Kyriakidis AV, Karydakis P, Neofytou N, et al. Plasmapheresis in the management of acute severe hyperlipidemic pancreatitis: report of 5 cases. Pancreatology. 2005; 5(2-3): 201-4. PMid:15855816 http://dx.doi.org/10.1159/000085272

[14] Chen JH, Yeh JH, Lai HW, et al. Therapeutic plasma exchange in patients with hyperlipidemic pancreatitis. World J Gastroenterol. 2004 Aug 1; 10(15): 2272-4. PMid:15259080 